\title{
Avaliação da qualidade físico -química e microbiológica das águas utilizadas pelos animais do Parque Municipal da Matinha, Itapetinga, Bahia, Brasil
}

Evaluation of the physicochemical and microbiological quality of the water used by the animals in the Parque Municipal da Matinha, Itapetinga, Bahia, Brazil

Evaluación de la calidad fisicoquímica y microbiológica del agua utilizada por los animales en el Parque Municipal da Matinha, Itapetinga, Bahía, Brasil

Marilene Souza Oliveira ORCID: https://orcid.org/0000-0002-1585-8902 Universidade Federal da Bahia, Brasil E-mail: souzaoliveira.mari@gmail.com

Ricardo Evangelista Fraga ORCID: https://orcid.org/0000-0001-9345-4869 Universidade Federal da Bahia, Brasil E-mail: ricardoefraga@ hotmail.com

Caique Dos Santos Aguiar ORCID: https://orcid.org/0000-0002-3714-1988 Universidade Federal da Bahia, Brasil

E-mail: caique1704@gmail.com

Deivson Araújo Brandão

ORCID: https://orcid.org/0000-0001-6678-7836 Universidade Federal da Bahia, Brasil E-mail: deivson11araujo@gmail.com

Deborah Froes de Oliveira

ORCID: https://orcid.org/0000-0003-4253-3078 Parque Municipal da Matinha, Brasil E-mail: deborahmedvet@hotmail.com

Fábio Viana Santos

ORCID: https://orcid.org/ 0000-0002-8978-7801 Secretaria Municipal de Meio Ambiente de Itapetinga, Brasil E-mail: fabioviana.pedagogo@gmail.com

Tiago Sousa de Queiroz

ORCID: https://orcid.org/0000-0002-9694-6962 Universidade Federal da Bahia, Brasil

E-mail: thy.queiroz@hotmail.com

Laize Tomazi

ORCID: https://orcid.org/0000-0003-0977-8508 Universidade Federal da Bahia, Brasil

E-mail: laizetomazi@yahoo.com.br

Mariane Amorim Rocha

ORCID: https://orcid.org/0000-0002-6185-8663 Universidade Federal da Bahia, Brasil

E-mail: anee.bio@hotmail.com

Márcio Borba da Silva

ORCID: https://orcid.org/0000-0002-6497-7924 Universidade Federal da Bahia, Brasil E-mail: biolmarcioborba@gmail.com

\section{Resumo}

Este trabalho teve como objetivo avaliar a qualidade das águas utilizadas pelos animais do Parque Municipal da Matinha, Itapetinga, Bahia, através das análises físico-químicas e microbiológicas, observando a adequação aos parâmetros estabelecidos para águas de classe 3 descritos na Resolução CONAMA N ${ }^{\circ}$ 357/ 2005. Foram coletadas entre os meses de julho a outubro de 2021, 60 amostras de água de 15 ambientes (tanque central, cozinha, lagos que cercam as ilhas dos macacos (ilha pequena e ilha grande), dos jacarés, além dos bebedouros presentes nos variados recintos). As análises foram realizadas utilizando as metodologias analíticas contidas no Standard methods for the examination of water and wastewater. Os resultados apontam que as águas utilizadas pelos animais do Parque Municipal da Matinha, Itapetinga Bahia apresentaram conformidade na maioria dos parâmetros físico-químicos 
avaliados. As amostras de abastecimento de água do parque apresentaram conformidade com a legislação vigente, isto é, próprias para a dessendentação dos animais. Contudo inconformidades foram registradas nos parâmetros microbiológicos para a maioria dos recintos dos animais indicando assim a necessidade de aumentos na frequência de higienização e desinfecção nos bebedouros. Os lagos avaliados revelaram contaminação fecal recente nas águas destes ambientes, além de inconformidades para alguns parâmetros físico-químicos. Deste modo renovação destas águas aliada a um sistema de filtração pode melhorar a sua qualidade. Portanto é evidente que o monitoramento da qualidade físico-química e microbiológica das águas utilizadas pelos animais contribui efetivamente para o diagnóstico e melhorias no manejo do parque.

Palavras-chave: Parque municipal; Qualidade da água; Matinha, Bahia.

\begin{abstract}
This study aimed to evaluate the quality of the water used by the animals of the Parque Municipal da Matinha, Itapetinga, Bahia, through physical-chemical and microbiological analyses, observing the adequacy to the parameters established for class 3 waters described in CONAMA Resolution No. 357 / 2005. From July to October 2021, 60 water samples were collected from 15 environments (central tank, kitchen, lakes that surround the monkey islands (small island and large island), caimans, in addition to the drinking fountains present in different venues). The analyzes were performed using the analytical methodologies contained in the Standard methods for the examination of water and wastewater. The results indicate that the waters used by the animals of the Parque Municipal da Matinha, Itapetinga Bahia showed compliance in most of the physical-chemical parameters evaluated. The park's water supply samples complied with current legislation, that is, they were suitable for the animals to drink water. However, nonconformities were recorded in the microbiological parameters for most animal enclosures, thus indicating the need for increases in the frequency of cleaning and disinfection in the drinking fountains. The lakes evaluated revealed recent fecal contamination in the waters of these environments, in addition to nonconformities for some physicalchemical parameters. In this way, the renewal of these waters combined with a filtration system can improve their quality. Therefore, it is evident that the monitoring of the physical-chemical and microbiological quality of the waters used by the animals effectively contributes to the diagnosis and improvements in the management of the park.
\end{abstract}

Keywords: Municipal park; Water quality; Matinha, Bahia.

\title{
Resumen
}

Este estudio tuvo como objetivo evaluar la calidad del agua utilizada por los animales del Parque Municipal da Matinha, Itapetinga, Bahia, a través de análisis físico-químicos y microbiológicos, observando la adecuación a los parámetros establecidos para aguas de clase 3 descritos en la Resolución CONAMA N ${ }^{\circ}$ 357/2005. Entre julio y octubre de 2021 se recolectaron 60 muestras de agua de 15 ambientes (tanque central, cocina, lagunas aledañas a las islas de los monos (isla pequeña e isla grande), caimanes, además de los bebederos presentes en diferentes recintos). Los análisis se realizaron utilizando las metodologías analíticas contenidas en los Métodos estándar para el análisis de aguas y aguas residuales. Los resultados indican que las aguas utilizadas por los animales del Parque Municipal da Matinha, Itapetinga Bahia, mostraron cumplimiento en la mayoría de los parámetros físico-químicos evaluados. Las muestras de abastecimiento de agua del parque cumplían con la legislación vigente, es decir, eran aptas para que los animales bebieran agua. Sin embargo, se registraron no conformidades en los parámetros microbiológicos para la mayoría de los recintos de animales, lo que indica la necesidad de aumentar la frecuencia de limpieza y desinfección en los bebederos. Los lagos evaluados revelaron contaminación fecal reciente en las aguas de estos ambientes, además de inconformidades para algunos parámetros físico-químicos. De esta forma, la renovación de estas aguas combinada con un sistema de filtración puede mejorar su calidad. Por lo tanto, se evidencia que el monitoreo de la calidad físicoquímica y microbiológica del agua utilizada por los animales contribuye efectivamente al diagnóstico y mejoras en la gestión del parque.

Palabras clave: Parque municipal; Calidad del agua; Matinha, Bahía.

\section{Introdução}

A água é o principal componente fundamental e indispensável para sobrevivência de qualquer espécie, devendo estar disponível em quantidade e qualidade inclusive na produção animal, quer seja para a dessedentação dos animais como na higienização das instalações e como veículo para retirada dos dejetos (Pereira et al., 2009). Contudo a água potável vem passando por uma certa escassez de acordo Bordalo et al (2017), fruto da degradação ambiental e contaminação dos recursos hídricos.

O Conselho Nacional do Meio Ambiente (CONAMA) por meio do artigo $4^{\circ}$ da Resolução 375/2005, classifica as águas doces em cinco classes diferentes, sendo que a classe 3 pode ser destinada à dessedentação de animais, devendo seguir 
alguns padrões de potabilidade, livres de contaminantes para a saúde e bem estar dos animais (BRASIL, 2005), conforme preconiza a referida resolução.

Os parâmetros microbiológicos e físico-químicos determinam as características de potabilidade necessárias para que a água seja propícia para o consumo, proporcionando melhor qualidade de vida para os animais que vivem ali. Os parâmetros químicos são importantes para caracterização da qualidade da água, permitindo detectar se há alguma substância presente na água, podendo assim, dentre ouras coisas, determinar nível de contaminação, evidenciando os picos de concentração de poluentes tóxicos. (Veiga, 2005).

Nas análises bacteriológicas, utiliza-se bactérias do grupo dos coliformes que atuam como indicadores de poluição fecal, pois estão sempre presentes no trato intestinal de animais homeotérmicos (aves e mamíferos) (Fernandes et al., 2021). A determinação de Escherichia coli é extremamente preconizada nas análises microbiológicas por indicar contaminação fecal, pois esta bactéria apresenta origem exclusivamente fecal, refletindo assim a qualidade higiênico-sanitária da água (APHA, 2017; CETESB, 2018).

Estudos realizados por Dubos e Schaedler (1961) e Cross-Mellor et al (2000) apontam que águas contaminadas por $E$ coli apresentam endotoxinas que desencadeiam a perda de peso em ratos, devido a desidratação provocada pela redução do consumo hídrico. Segundo Willms et al (2002) bovinos evitaram consumir águas contaminadas por E coli, sendo aqueles que consumiram água isentas de E coli ganharam peso (cerca de 9 a $23 \%$ ) quando comparado com os que ingeriram águas contaminadas por fezes, sendo que estes últimos passaram mais tempo em descanso e menor tempo em pastejo. Logo águas contaminadas por fezes podem impactar negativamente no consumo hídrico e tempo de forrageio dos animais, interferindo assim no seu crescimento, saúde e bem estar.

Animais em cativeiro estão predispostos a variados níveis de estresse, provocando alterações funcionais, que podem tornar os animais enfraquecidos, sem habilidades físicas e psicológicas (Onsini e Bondan, 2006) tornando-os mais susceptíveis a baixas do sistema imunológico, e consequentemente a doenças (Lourenço, 2014; Pereira, 2015). Neste interim, o bem-estar animal assume grande importância na manutenção dos animais nos zoológicos, propiciando os animais: ausência de fome, sede e desnutrição, desconforto, dor, injúrias e doenças, podendo assim expressar o comportamento natural de espécie sem medo e estresse (Saad et al., 2011).

Pensando no bem estar dos animais cativos e sabendo que fornecer uma água adequada para o consumo pode melhorar a qualidade de vida desses animais, o presente estudo teve como objetivo avaliar a qualidade das águas utilizadas pelos animais do Parque Municipal da Matinha, Itapetinga, Bahia, através das análises físico-químicas e microbiológicas, observando a adequação aos parâmetros estabelecidos para águas de classe 3 descritos na Resolução CONAMA N 357, de 17 de março de 2005, fornecendo assim subsídios para o manejo no parque.

\section{Metodologia}

O Parque Municipal da Matinha, localizado no perímetro urbano do município de Itapetinga, sudoeste da Bahia, compreende a área circundada pelo Rio Catolé Grande até a ponte próxima à Estação Rodoviária (Figura 1). Possui extensão de 24 hectares, sendo destes, apenas 10 hectares de Mata Atlântica. (Kulka, 2014).

Segundo Coelho (2015) a origem deste parque vem da desapropriação de uma área florestal situada no município, aglutinada dentro de uma fazenda denominada "Volta Grande". O Parque abriga remanescente de Mata Atlântica, animais silvestres e exóticos, o que pode caracterizá-lo como um Jardim Municipal (Kulka, 2014).

O parque tem como objetivo preservar e conservar a representação da Mata Atlântica, servindo, de refúgio para muitas espécies, entre elas animais silvestres oriundos do tráfico e que muitas vezes não tem mais condições de voltar para 
natureza, além de espécimes exóticos oriundos de outros zoológicos, contribuindo em ações educacionais, culturais e recreativos (Itapetinga, 1994).

Figura 1: Localização da área de estudo, Parque Municipal da Matinha, Itapetinga, Bahia, Brasil.

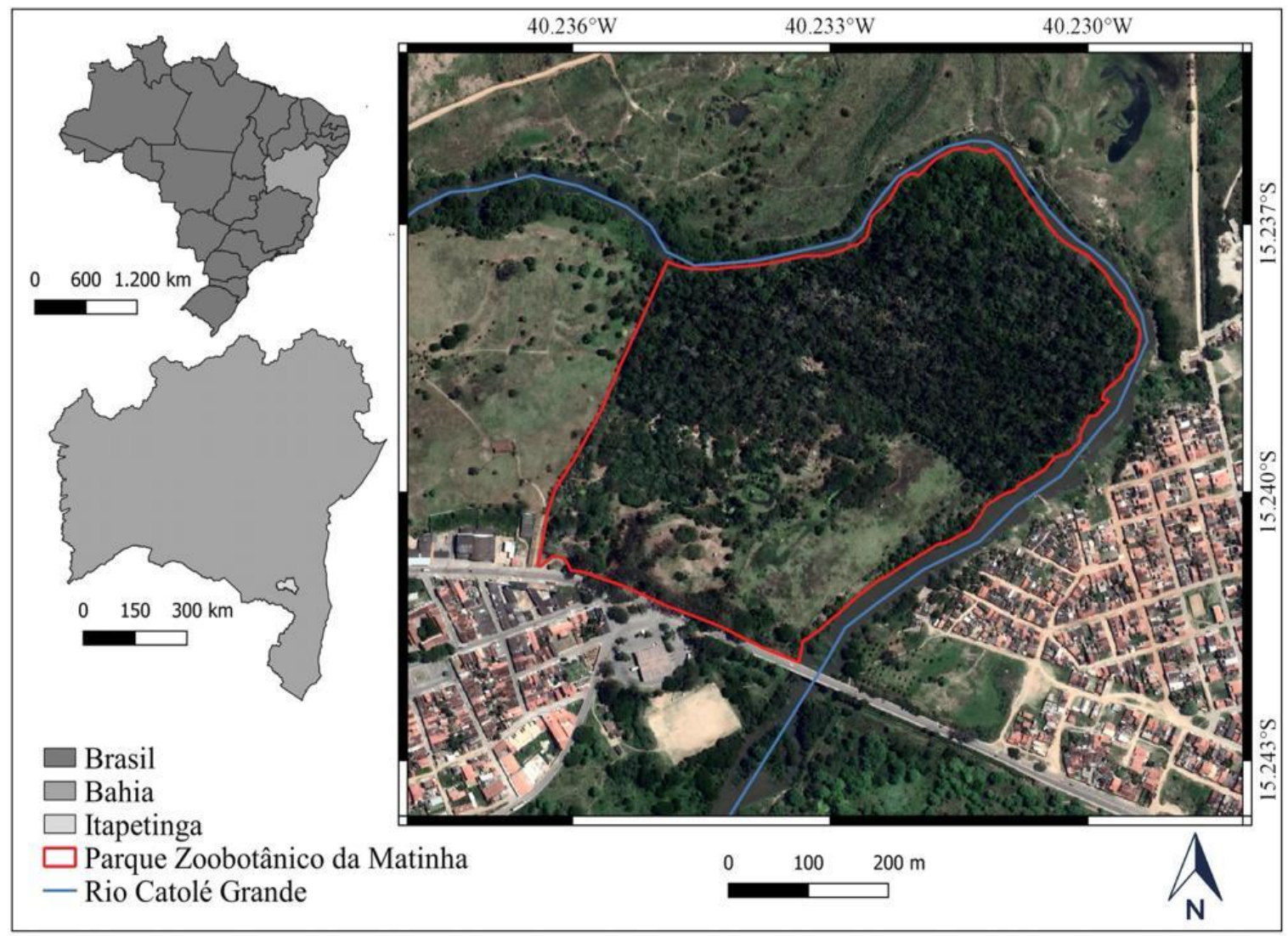

Fonte: Autores.

De acordo Freitas et al. (2007), o parque é considerado de grande relevância para a sociedade, pois é a única área de proteção ambiental do município e o único zoológico do interior da Bahia. A sua configuração inclui recintos do zoológico circundados pela vegetação de mata atlântica da reserva.

O Parque Municipal da Matinha tem um total de 36 recintos, sendo que apenas 21 recintos estavam ocupados no momento de coleta das amostras, uma vez que o Parque está passando por uma reestruturação de modo a atender as solicitações dos órgãos ambientais. Abrigava no momento das coletas 21 espécies de animais cativos, sendo 04 espécies de mamíferos, 05 espécies de répteis e 11 espécies de aves (Tabela 1). 
Tabela 1: Animais presentes nos recintos do Parque Municipal da Matinha, Itapetinga, Bahia, Brasil.

\begin{tabular}{l|l}
\hline \multicolumn{1}{c|}{ Nome Científico } & Nome Comum \\
\hline Ordem Testudines &
\end{tabular}

\section{Família Testudinidae}

Chelonoidis carbonaria (Spix, 1824)

Chelonoidis denticulatus (Linnaeus, 1766)

Classe Lepidosauria

Ordem Squamata

Família Boidae

Boa constrictor (Linnaeus, 1758)

Família Pythonidae

Malayopython reticulatus (Schneider, 1801)

Classe Archeosauria

Ordem Crocodylia

Família Alligatoridae

Caiman latirostris (Daudin, 1801)

Aves

Ordem Pisttaciformes

\section{Família Psittacidae}

Ara ararauna (Linnaeus, 1758)

Ara chloropterus Gray, 1859

Aratinga auricapillus (Kuhl, 1820)

Pionus maximiliani (Kuhl, 1820)

Psittacara leucophthalmus (Statius Muller, 1776)

Ordem Falconiformes

Família Falconidae

Caracara plancus (Miller, 1777)

Ordem Galliformes

Família Cracidae

Ortalis guttata (Spix, 1825)

Família Phasianidae

Pavo cristatus Linnaeus, 1758

Ordem Piciformes

\section{Família Ramphastidae}

Ramphastos toco Statius Muller, 1776

\section{Ordem Cathartiformes}

\section{Família Cathartidae}

Sarcoramphus papa (Linnaeus, 1758)
Carcará

Jabuti piranga

Jabuti tinga

Jiboia

Píton

Jacaré de papo amarelo

$$
\begin{aligned}
& \text { Arara Canindé } \\
& \text { Arara vermelha }
\end{aligned}
$$

Aratinga-de-testa-vermelha

$$
\text { Maitaca }
$$

Aratinga de bando

Aracuã - pintado

Pavão

$$
\text { Tucanuçu }
$$

Urubu rei 


\section{Ordem Struthioniformes}

Família Struthionidae

Struthio camelus Linnaeus, 1758

Avestruz

\section{Classe Mammalia}

Ordem Carnivora

Família Canidae

Cerdocyon thous (Linnaeus, 1766)

Raposa

Família Felidae

Panthera leo (Linnaeus, 1758)

Leão

Puma concolor Linnaeus, 1771

Suçuarana

Ordem Primates

Família Cebidae

Sapajus libidinosus (Spix, 1823)

Macaco prego

Fonte: Autores.

Os recintos foram recentemente reformados e enriquecidos ambientalmente de modo a contribuir para o bem estar dos animais e atendem a instrução normativa nº 07/2015 do IBAMA que aponta estruturas mínimas que cada recinto deve conter de acordo a espécie alojada. Todos os recintos recebem água tratada proveniente da rede de distribuição municipal que é armazenada em um tanque central e então distribuída para os recintos por meio de tubulações de PVC. Apenas os recintos da jiboia, quarentena e carcará recebem água diretamente da rede de distribuição municipal.

De modo geral os recintos são construídos em alvenaria nas paredes e tela, contando ainda com o chão do recinto de constituição arenosa. (Figura 2). Há ainda duas ilhas onde ficam alocados os macacos pregos (Sapajus sp), isoladas por um corpo aquático (Ilha pequena e grande, Figuras $2 \mathrm{~b}$ e $2 \mathrm{c}$, respectivamente). A ilha pequena tem medida de $141,82 \mathrm{~m}^{2}$ correspondendo um total de 347,68 $\mathrm{m}^{2}$ quando incluído a porção aquática. A ilha grande área total de $760,74 \mathrm{~m}^{2}$. Por fim existe ainda o recinto dos jacarés constituído por um lago artificial com área total de 285,62 m² (Figura 2a).

Cada recinto apresenta um bebedouro coletivo para os animais ali confinados (Figura 2). Os bebedouros são confeccionados em alvenaria, permanecendo fixos ao solo. No recinto dos avestruzes o bebedouro presente é uma caixa d'água de polietileno com capacidade para 500 litros (Figura 2f). 
Figura 2: Aspecto dos ambientes e recintos do Parque Municipal da Matinha, Itapetinga, Bahia amostrados no estudo: a) Lago do jacaré; b) Ilha pequena dos macacos; c) Ilha grande dos macacos; d) Recinto do carcará; e) Quarentena; f) Recinto do avestruz.
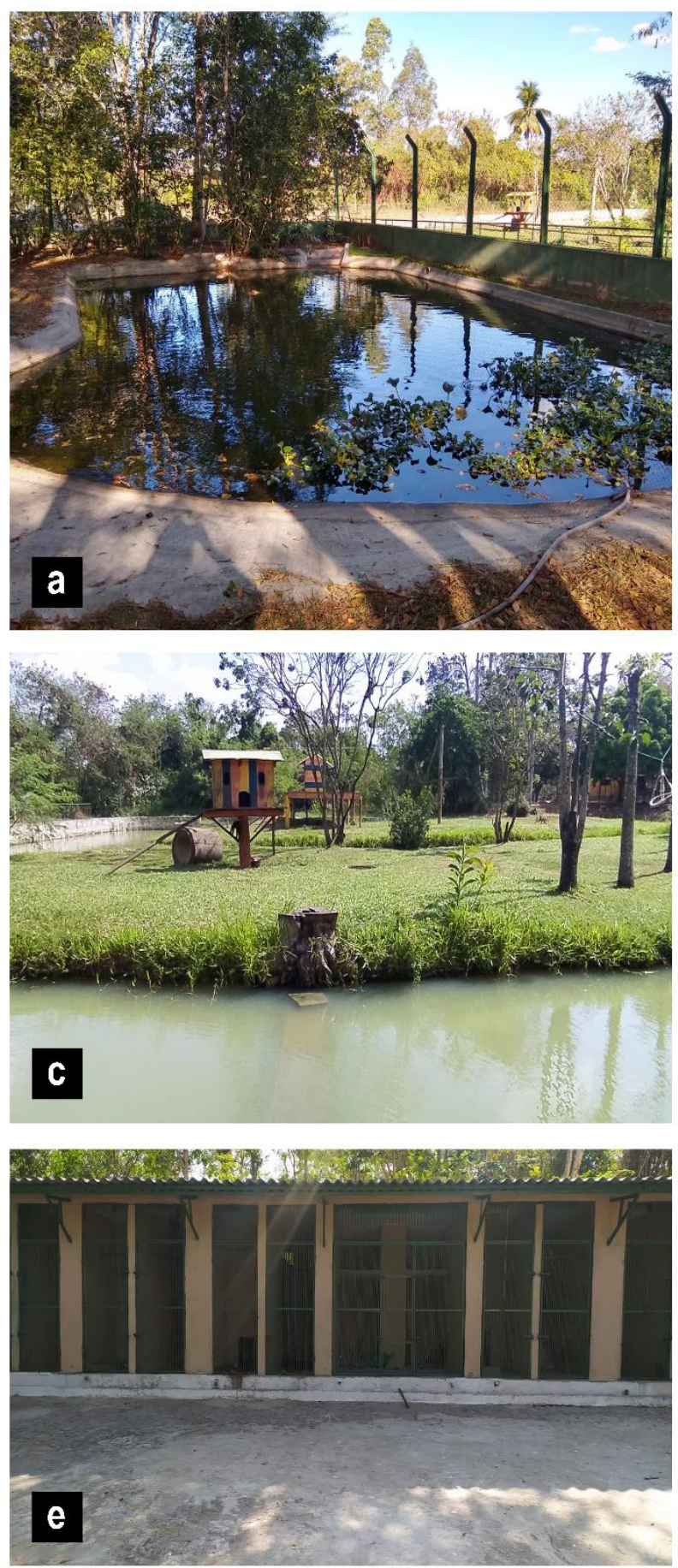
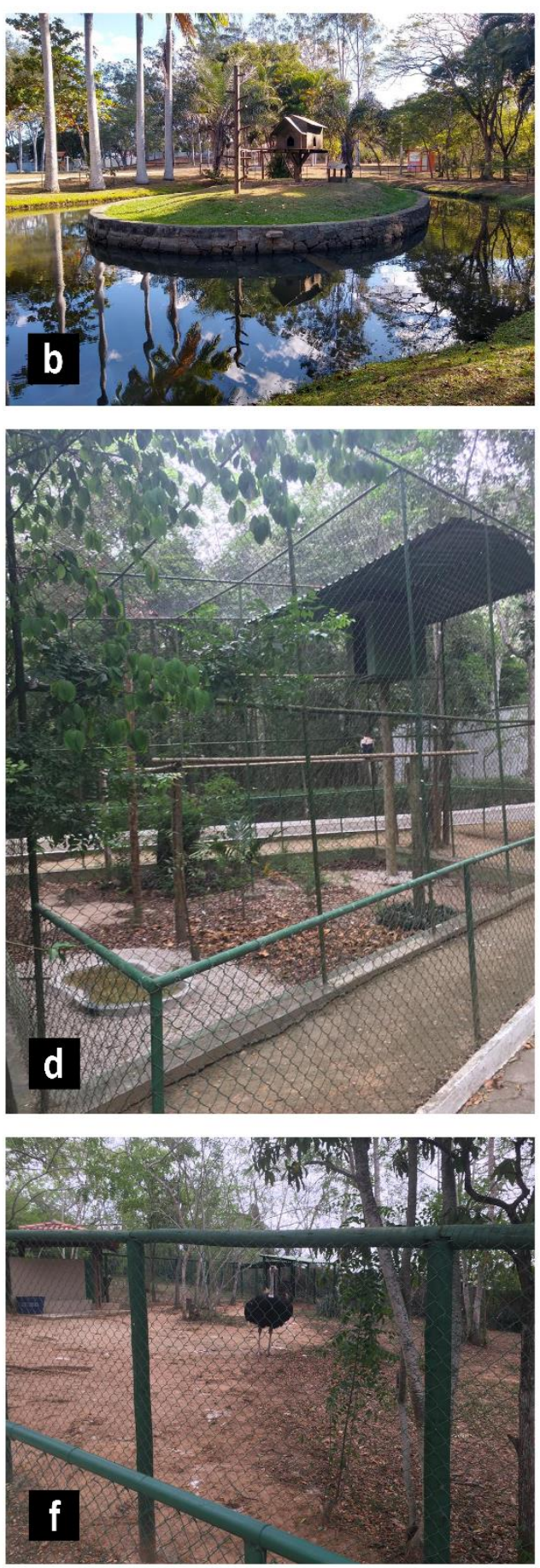

Fonte: Autores. 
Figura 3: Aspecto dos ambientes e recintos do Parque Municipal da Matinha, Itapetinga, Bahia amostrados no estudo: g) Recinto da jiboia; h) Recinto do periquito; i) Recinto da píton; j) Recinto da onça; k) Recinto da arara; 1) Recinto do jabuti.
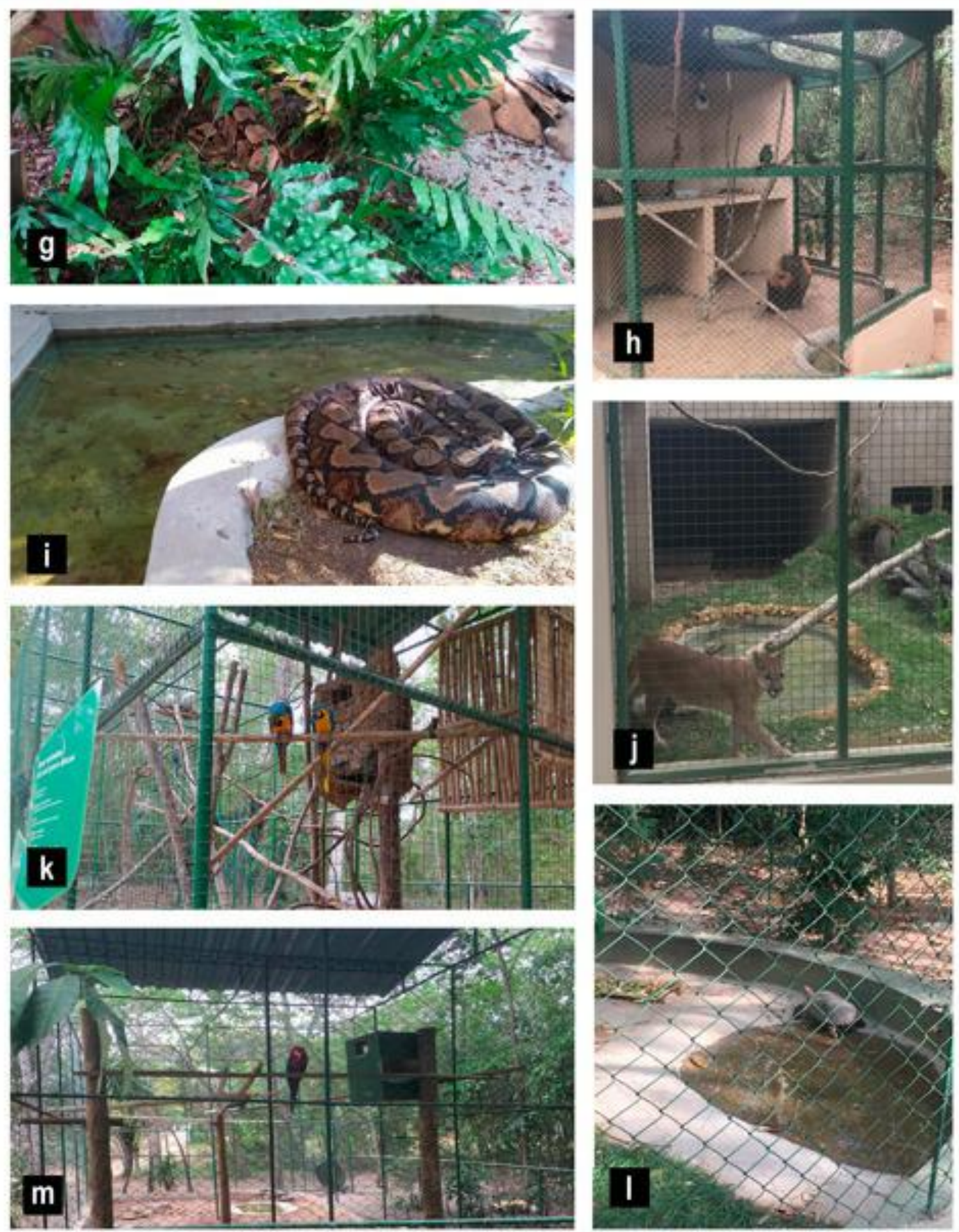

Fonte: Autores.

Este trabalho trata-se de uma pesquisa quantitativa descritiva (Dalfovo et al., 2008; Pereira et al., 2018). Assim, foram coletadas 60 amostras de água do Parque Municipal da Matinha, Itapetinga, Bahia, entre os meses de julho a outubro de 2021. 
Foram selecionados 15 ambientes para serem avaliados, sendo classificados em fontes de abastecimento do parque (tanque central e cozinha), lagos que cercam as ilhas dos macacos (ilha pequena e ilha grande) e o que abrigava os jacarés, além dos bebedouros presentes nos variados recintos (Tabela 2).

Tabela 2: Ambientes amostrados no Parque Municipal da Matinha, Itapetinga, Bahia, Brasil.

\begin{tabular}{|c|c|c|c|}
\hline Ambientes & Locais & Espécies Presentes & $\mathrm{N}^{0}$ de indivíduos \\
\hline \multirow{2}{*}{ Abastecimento } & Tanque & - & - \\
\hline & Cozinha & - & - \\
\hline \multirow{3}{*}{ Lagos } & Ilha Grande & S. libidinosus & 12 \\
\hline & Jacarés & C. latirostris & 2 \\
\hline & Ilha Pequena & S. libidinosus & 3 \\
\hline \multirow{10}{*}{ Recintos } & Quarentena & C. thous e S. libidinosus & 2 \\
\hline & Araras & A. ararauna e A. chloropterus & 8 \\
\hline & Avestruz & S. camelus & 2 \\
\hline & Carcará & C. plancus & 2 \\
\hline & Jabutis & C. carbonaria e C. denticulatus & 10 \\
\hline & Jiboia & B. constrictor & 3 \\
\hline & Leão & P. leo & 1 \\
\hline & Onça & P. concolor & 2 \\
\hline & Maitaca & P.maximiliani e E. aurea & 3 \\
\hline & Píton & M. reticulatus & 1 \\
\hline
\end{tabular}

Fonte: Autores.

As amostras de águas para as análises físico-químicas foram coletadas em frascos de polietileno inerte com capacidade para 1L de água. Já as bacteriológicas foram coletadas em frascos de vidro esterilizado com capacidade de $100 \mathrm{~mL}$, tampa rosca previamente autoclavados, tomando-se todos os cuidados para que o processo ocorresse de maneira asséptica. Após a coleta, os frascos com as amostras de água foram colocados em caixas isotérmicas $\left(2\right.$ a $\left.8^{\circ} \mathrm{C}\right)$ e transportadas imediatamente para o Laboratório de Análises de Água da Empresa Baiana de Águas e Saneamento EMBASA em Vitória da Conquista, Bahia para as análises.

Os parâmetros físico-químicos e microbiológicos utilizados para avaliar a qualidade da água do Parque Municipal da Matinha podem ser observados na Tabela 3. Antes da realização das análises todas as amostras foram ambientalizadas, e quando as amostras chegaram à temperatura ambiente os ensaios foram realizados. 
Tabela 3: Parâmetros físico-químicos, microbiológico e metodologia empregada para a determinação da qualidade da água utilizada por animais no Parque Municipal da Matinha, Itapetinga - Bahia.

\begin{tabular}{lcc}
\hline Parâmetros & Unidade & Método \\
\hline Cloreto & $\mathrm{mg} \mathrm{L}^{-1}$ & Titulométrico \\
Condutividade elétrica & $\mu \mathrm{S} / \mathrm{cm}$ & Condutivimetro \\
Cor Aparente & $\mathrm{mg} \mathrm{Pt} \mathrm{Co} \mathrm{L}^{-1}$ & Espectrofotométrico \\
Demanda Bioquímica de Oxigênio (DBO) & $\mathrm{mg} \mathrm{L}^{-1}$ & Incubação 5/20 \\
Demanda Química de Oxigênio (DQO) & $\mathrm{mg} \mathrm{L}^{-1}$ & Espectrofotométrico \\
pH & - & pH-metro AZ86505 \\
Sólidos Dissolvidos Totais & $\mathrm{mg} \mathrm{L}^{-1}$ & Condutivimetro \\
Turbidez & $\mathrm{NTU}$ & Turbidimétrico \\
Coliformes Totais Quantitativo & $\mathrm{NMP} / 100 \mathrm{~mL}$ & Quant Tray \\
Escherichia coli Quantitativo & $\mathrm{NMP} / 100 \mathrm{~mL}$ & Quant Tray \\
\hline
\end{tabular}

Fonte: Autores.

As análises físico-químicas foram realizadas utilizando as metodologias analíticas contidas no livro "Standard methods for the examination of water and wastewater" (APHA, 2017). A DBO e a DQO foram analisadas apenas para os lagos. Os limites de aceitação utilizados neste estudo foram os estabelecido pela resolução CONAMA $357 / 2005$ para classe 3 Dessedentação de animais.

Os parâmetros microbiológicos utilizados foram à presença de bactérias dos grupos coliformes totais e Escherichia coli, utilizando-se o reagente Colilert pelo método quantitativo (APHA 2017). Os resultados foram expressos em Número Mais Provável - NMP/100 mL consultando a tabela fornecida pelo fabricante.

Os valores de cada parâmetro avaliado foram tabulados e analisados através de estatística descritiva (média \pm desvio padrão) com o auxílio do software GraphPad Prism® versão 5. A adequação da água às legislações pertinentes (Resolução CONAMA 357/2005) foi apresentada através da frequência relativa das amostras em conformidade ou desconformidade com a referida legislação.

\section{Resultados}

Os resultados das variáveis físico-químicas e microbiológicas avaliadas no presente estudo encontram-se na tabela 4. De modo geral, as águas utilizadas para o abastecimento e preparo de alimentos (tanque central e cozinha, respectivamente) do Parque Municipal da Matinha apresentam boa qualidade e em conformidade com a resolução 357/2005 do CONAMA para águas de classe 3 utilizadas para dessedentação de animais, quer seja os aspectos físico-químicos, quer seja os microbiológicos, com ausência de coliformes totais e de E. coli em todas as amostras analisadas (tabela 5). Este mesmo padrão foi evidenciado para as amostras provenientes da quarentena (Tabela 5).

Para os ambientes de lagos artificiais (ilha grande dos macacos, ilha pequena dos macacos e lago dos jacarés) os resultados obtidos revelaram desconformidade (acima do permitido) com o preconizado pela referida resolução no que tange aos parâmetros cor para as águas da ilha grande e dos jacarés, $\mathrm{pH}$ para o lago dos jacarés, DBO e E. coli para todos os lagos analisados (Tabela 5). Todas as amostras analisadas apresentaram positividade para coliformes totais. O CONAMA que 
regulamenta as normas de potabilidade das águas brasileiras, na Resolução de № 357 de 17 de março de 2005, não determina limites máximos de coliformes totais para dessedentação animal.

Analisando as águas presentes nos recintos, observa-se que a maioria dos recintos estão com os parâmetros físicoquímicos em conformidade com o preconizado pela resolução CONAMA supra citada (Tabela 5). Desconformidade foram registradas no parâmetro $\mathrm{pH}$ que estava mais alcalino, acima do limite em 50\% das amostras dos recintos dos periquitos e da jiboia (Tabela 5). Do ponto de vista microbiológico, todos os recintos avaliados apresentaram positividade para coliformes totais e E. coli. Os recintos das araras e avestruz (100\% de desconformidade), carcará (75\%), onça (50\%) jiboia e leão (25\%) apresentaram amostras com concentração de E.coli superior ao preconizado pela legislação (Tabela5). 


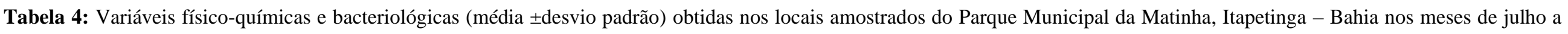
outubro de 2021. Dados de algumas variáveis estabelecido pela resolução CONAMA 357/2005 para águas de classe 3.

\begin{tabular}{|c|c|c|c|c|c|c|c|c|c|c|c|c|c|c|c|c|}
\hline \multirow{2}{*}{ Parâmetros } & \multirow{2}{*}{ 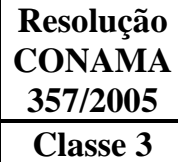 } & \multicolumn{2}{|c|}{ Abastecimento } & \multicolumn{3}{|c|}{ Lagos } & \multicolumn{10}{|c|}{ Recintos } \\
\hline & & Tanque & Cozinha & Grande & Jacaré & Pequeno & Araras & Avestruz & Carcará & Jabuti & Jiboia & Leão & Onça & Periquitos & Píton & Quarentena \\
\hline $\begin{array}{l}\text { Cloreto (mg } \\
\left.\mathrm{L}^{-1}\right)\end{array}$ & $\leq 250$ & $\begin{array}{c}23,0 \pm \\
3,2\end{array}$ & $\begin{array}{c}58,2 \pm \\
0,1\end{array}$ & $\begin{array}{c}24,5 \pm \\
1,3\end{array}$ & $\begin{array}{c}24,0 \pm \\
1,4\end{array}$ & $\begin{array}{c}24,1 \pm \\
0,9\end{array}$ & $\begin{array}{c}21,0 \pm \\
0,2\end{array}$ & $\begin{array}{c}22,6 \pm \\
0,3\end{array}$ & $\begin{array}{c}40,7 \pm \\
24,1\end{array}$ & $\begin{array}{c}23,1 \pm \\
3,2\end{array}$ & $\begin{array}{c}34,5 \pm \\
18,7\end{array}$ & $\begin{array}{c}25,7 \pm \\
1,5\end{array}$ & $\begin{array}{c}22,1 \pm \\
3,2\end{array}$ & $\begin{array}{c}21,8 \pm \\
0,1\end{array}$ & $\begin{array}{c}23,0 \pm \\
1,0\end{array}$ & $21,5 \pm 3,0$ \\
\hline $\begin{array}{l}\text { Condutividade } \\
\text { Elétrica } \\
(\mu \mathrm{S} / \mathrm{cm})\end{array}$ & $\begin{array}{c}\text { Não } \\
\text { Informado }\end{array}$ & $\begin{array}{r}127,4 \\
\pm 12,1\end{array}$ & $\begin{array}{c}166,5 \pm \\
89,7\end{array}$ & $\begin{array}{c}131,2 \pm \\
6,3\end{array}$ & $\begin{array}{c}237,6 \pm \\
36,3\end{array}$ & $\begin{array}{c}138,6 \pm \\
4,0\end{array}$ & $\begin{array}{c}166,8 \pm \\
26,3\end{array}$ & $\begin{array}{c}134,6 \pm \\
6,5\end{array}$ & $\begin{array}{c}207,5 \pm \\
59,9\end{array}$ & $\begin{array}{r}183,9 \\
\pm 50,9\end{array}$ & $\begin{array}{l}98,5 \pm \\
75,5\end{array}$ & $\begin{array}{l}192,3 \\
\pm 6,9\end{array}$ & $\begin{array}{r}160,2 \\
\pm 40,7\end{array}$ & $\begin{array}{c}155,0 \pm \\
18,8\end{array}$ & $\begin{array}{c}148,30 \pm \\
12,71\end{array}$ & $118,5 \pm 9,1$ \\
\hline $\begin{array}{l}\text { Cor }\left(\mathrm{mg} \mathrm{L}^{-1} \mathrm{Pt}\right. \\
\text { Co) }\end{array}$ & $\leq 75$ & $\begin{array}{c}1,3 \pm \\
0,2\end{array}$ & $\begin{array}{c}0,4 \pm \\
0,5\end{array}$ & $\begin{array}{c}82,8 \pm \\
39,1\end{array}$ & $\begin{array}{c}100,0 \pm \\
444,5\end{array}$ & $\begin{array}{c}37,7 \pm \\
4,4\end{array}$ & $\begin{array}{c}32,1 \pm \\
17,1\end{array}$ & $\begin{array}{c}6,77 \pm \\
0,27\end{array}$ & $\begin{array}{c}8,1 \pm \\
4,4\end{array}$ & $\begin{array}{c}13,0 \pm \\
13,1\end{array}$ & $\begin{array}{c}5,20 \pm \\
2,0\end{array}$ & $\begin{array}{c}9,1 \pm \\
4,5\end{array}$ & $\begin{array}{c}8,3 \pm \\
8,5\end{array}$ & $12,9 \pm 6,7$ & $\begin{array}{c}11,8 \pm \\
6,5\end{array}$ & $1,9 \pm 0,5$ \\
\hline $\mathrm{DBO}\left(\mathrm{mg} \mathrm{L}^{-1}\right)$ & $\leq 10$ & - & - & $\begin{array}{c}12,4 \pm \\
5,7\end{array}$ & $\begin{array}{c}88,2 \pm \\
67,5\end{array}$ & $\begin{array}{c}9,6 \pm \\
6,5\end{array}$ & - & - & - & - & - & - & - & - & - & - \\
\hline DQO & $\begin{array}{c}\text { Não } \\
\text { Informado }\end{array}$ & - & - & $\begin{array}{c}28,0 \pm \\
28,9\end{array}$ & $\begin{array}{c}59,2 \pm \\
57,4\end{array}$ & $\begin{array}{c}31,4 \pm \\
33,0\end{array}$ & - & - & - & - & - & - & - & - & - & - \\
\hline $\mathrm{pH}$ & 6,0 a 9,0 & $\begin{array}{c}7,1 \pm \\
0,5\end{array}$ & $\begin{array}{c}6,8 \pm \\
0,2\end{array}$ & $\begin{array}{c}7,4 \pm \\
0,3\end{array}$ & $\begin{array}{c}8,8 \pm \\
0,4\end{array}$ & $\begin{array}{c}7,2 \pm \\
0,5\end{array}$ & $\begin{array}{c}7,6 \pm \\
0,3\end{array}$ & $7,9 \pm 0,1$ & $\begin{array}{c}7,9 \pm \\
1,2\end{array}$ & $\begin{array}{c}8,3 \pm \\
0,5\end{array}$ & $\begin{array}{c}8,4 \pm \\
1,3\end{array}$ & $\begin{array}{c}7,4 \pm \\
0,2\end{array}$ & $\begin{array}{c}7,9 \pm \\
0,9\end{array}$ & $\begin{array}{c}9,01 \pm \\
0,03\end{array}$ & $7,3 \pm 1,0$ & $7,3 \pm 0,1$ \\
\hline $\begin{array}{l}\text { Sólidos Totais } \\
\text { Dissolvidos } \\
\left(\mathrm{mg} \mathrm{L}^{-1}\right)\end{array}$ & $\leq 500$ & $\begin{array}{c}72,3 \pm \\
6,9\end{array}$ & $\begin{array}{l}96,2 \pm \\
52,5\end{array}$ & $\begin{array}{c}74,9 \pm \\
3,7\end{array}$ & $\begin{array}{c}135,0 \pm \\
22,0\end{array}$ & $\begin{array}{c}79,2 \pm \\
3,0\end{array}$ & $\begin{array}{c}96,8 \pm \\
13,3\end{array}$ & $\begin{array}{c}78,13 \pm \\
3,8\end{array}$ & $\begin{array}{c}120,6 \pm \\
35,2\end{array}$ & $\begin{array}{r}106,6 \\
\pm 29,8\end{array}$ & $\begin{array}{c}51,3 \pm \\
54,4\end{array}$ & $\begin{array}{c}86,5 \pm \\
47,1\end{array}$ & $\begin{array}{c}92,9 \pm \\
23,7\end{array}$ & $\begin{array}{c}69,58 \pm \\
37,16\end{array}$ & $\begin{array}{c}85,4 \pm \\
7,6\end{array}$ & $68,6 \pm 5,3$ \\
\hline $\begin{array}{l}\text { Turbidez } \\
\text { (UNT) }\end{array}$ & $\leq 100$ & $\begin{array}{c}0,4 \pm \\
0,3\end{array}$ & $\begin{array}{c}0,3 \pm \\
0,4\end{array}$ & $\begin{array}{c}26,1 \pm \\
7,5\end{array}$ & $\begin{array}{c}17,5 \pm \\
5,9\end{array}$ & $\begin{array}{c}10,2 \pm \\
6,6\end{array}$ & $\begin{array}{c}4,9 \pm \\
2,9\end{array}$ & $1,3 \pm 0,9$ & $\begin{array}{c}1,3 \pm \\
0,5\end{array}$ & $\begin{array}{c}7,3 \pm \\
5,4\end{array}$ & $\begin{array}{c}1,1 \pm \\
0,9\end{array}$ & $\begin{array}{c}1,1 \pm \\
1,1\end{array}$ & $\begin{array}{c}2,0 \pm \\
1,6\end{array}$ & $0,7 \pm 0,1$ & $1,3 \pm 0,7$ & $0,3 \pm 0,3$ \\
\hline $\begin{array}{l}\text { Coliformes } \\
\text { Totais } \\
\text { (NMP/100 } \\
\text { mL) }\end{array}$ & $\begin{array}{c}\text { Não } \\
\text { Informado }\end{array}$ & $\begin{array}{c}0,0 \pm \\
0,0\end{array}$ & $\begin{array}{c}0,0 \pm \\
0,0\end{array}$ & $\begin{array}{c}38552,0 \\
\pm \\
47117,0\end{array}$ & $\begin{array}{c}44190,0 \\
\pm \\
35455,0\end{array}$ & $\begin{array}{c}22401,0 \\
\pm \\
22577,0\end{array}$ & $\begin{array}{c}> \\
2419,0 \\
\pm 0,0\end{array}$ & $\begin{array}{c}>2419,0 \\
\pm 0,0\end{array}$ & $\begin{array}{c}2733,0 \\
\pm \\
1317,0\end{array}$ & $\begin{array}{c}3239,0 \\
\pm \\
1939,0\end{array}$ & $\begin{array}{c}3179,0 \\
\pm \\
3882,0\end{array}$ & $\begin{array}{c}1824,0 \\
\pm \\
2119,0\end{array}$ & $\begin{array}{c}1253,0 \\
\pm \\
1348,0\end{array}$ & $\begin{array}{c}2967,0 \pm \\
1096,0\end{array}$ & $\begin{array}{c}50327,0 \\
\pm \\
107126,0\end{array}$ & $0,0 \pm 0,0$ \\
\hline $\begin{array}{l}\text { Escherichia } \\
\text { coli } \\
(\mathrm{NMP} / 100 \\
\mathrm{mL})\end{array}$ & $\leq 200$ & $\begin{array}{c}0,0 \pm \\
0,0\end{array}$ & $\begin{array}{c}0,0 \pm \\
0,0\end{array}$ & $\begin{array}{c}8804,0 \\
\pm \\
20346,0\end{array}$ & $\begin{array}{c}3632,0 \\
\pm \\
8052,0\end{array}$ & $\begin{array}{c}280,4 \pm \\
282,2\end{array}$ & $\begin{array}{c}>2419,0 \\
\pm 0,0\end{array}$ & $\begin{array}{c}4126,0 \pm \\
505,5\end{array}$ & $\begin{array}{c}993,5 \pm \\
1025,0\end{array}$ & $\begin{array}{r}108,8 \\
\pm 89,4\end{array}$ & $\begin{array}{c}66,2 \pm \\
123,5\end{array}$ & $\begin{array}{c}513,3 \\
\pm \\
982,0\end{array}$ & $\begin{array}{c}8698,0 \\
\pm \\
9966,0\end{array}$ & $15,7 \pm 9,9$ & $\begin{array}{c}730,4 \pm \\
1287,0\end{array}$ & $0,0 \pm 0,0$ \\
\hline
\end{tabular}

Fonte: Autores. 


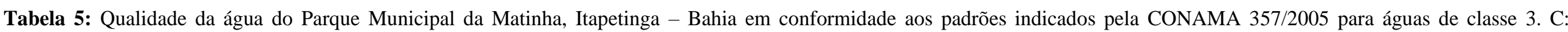
Conformidade; D: Desconformidade; \%: Porcentagem das amostras.

\begin{tabular}{|c|c|c|c|c|c|c|c|c|c|c|c|c|c|c|c|}
\hline \multirow[t]{2}{*}{ Ambientes } & \multirow[t]{2}{*}{ Locais } & \multicolumn{2}{|c|}{ Cloreto } & \multicolumn{2}{|c|}{ Cor } & \multicolumn{2}{|c|}{ DBO } & \multicolumn{2}{|c|}{ pH } & \multicolumn{2}{|c|}{$\begin{array}{c}\text { Sólidos Totais } \\
\text { Dissolvidos }\end{array}$} & \multicolumn{2}{|c|}{ Turbidez } & \multicolumn{2}{|c|}{$\begin{array}{c}\text { Escherichia } \\
\text { coli }\end{array}$} \\
\hline & & $\mathrm{C}(\%)$ & $\mathrm{D}(\%)$ & $\mathrm{C}(\%)$ & D $(\%)$ & $\mathrm{C}(\%)$ & D $(\%)$ & $\mathrm{C}(\%)$ & $\mathrm{D}(\%)$ & $\mathrm{C}(\%)$ & $\mathrm{D}(\%)$ & $\mathrm{C}(\%)$ & $\mathrm{D}(\%)$ & $\mathrm{C}(\%)$ & $\mathrm{D}(\%)$ \\
\hline \multirow{2}{*}{ Abastecimento } & Tanque & 100 & 0 & 100 & 0 & & & 100 & 0 & 100 & 0 & 100 & 0 & 100 & 0 \\
\hline & Cozinha & 100 & 0 & 100 & 0 & & & 100 & 0 & 100 & 0 & 100 & 0 & 100 & 0 \\
\hline \multirow{3}{*}{ Lagos } & Grande & 100 & 0 & 50 & 50 & 25 & 75 & 100 & 0 & 100 & 0 & 100 & 0 & 25 & 75 \\
\hline & Jacaré & 100 & 0 & 50 & 50 & 25 & 75 & 50 & 50 & 100 & 0 & 100 & 0 & 25 & 75 \\
\hline & Pequeno & 100 & 0 & 100 & 0 & 50 & 50 & 100 & 0 & 100 & 0 & 100 & 0 & 25 & 75 \\
\hline \multirow{10}{*}{ Recintos } & Araras & 100 & 0 & 100 & 0 & & & 100 & 0 & 100 & 0 & 100 & 0 & 0 & 100 \\
\hline & Avestruz & 100 & 0 & 100 & 0 & & & 100 & 0 & 100 & 0 & 100 & 0 & 0 & 100 \\
\hline & Carcará & 100 & 0 & 100 & 0 & & & 100 & 0 & 100 & 0 & 100 & 0 & 25 & 75 \\
\hline & Jabuti & 100 & 0 & 100 & 0 & & & 100 & 0 & 100 & 0 & 100 & 0 & 100 & 0 \\
\hline & Jiboia & 100 & 0 & 100 & 0 & & & 50 & 50 & 100 & 0 & 100 & 0 & 75 & 25 \\
\hline & Leão & 100 & 0 & 100 & 0 & & & 100 & 0 & 100 & 0 & 100 & 0 & 75 & 25 \\
\hline & Onça & 100 & 0 & 100 & 0 & & & 100 & 0 & 100 & 0 & 100 & 0 & 50 & 50 \\
\hline & Periquitos & 100 & 0 & 100 & 0 & & & 50 & 50 & 100 & 0 & 100 & 0 & 100 & 0 \\
\hline & Píton & 100 & 0 & 100 & 0 & & & 100 & 0 & 100 & 0 & 100 & 0 & 50 & 50 \\
\hline & Quarentena & 100 & 0 & 100 & 0 & & & 100 & 0 & 100 & 0 & 100 & 0 & 100 & 0 \\
\hline Total & & 100,0 & 0,0 & 93,3 & 6,7 & 60,0 & 40,0 & 90,0 & 10,0 & 100,0 & 0,0 & 100,0 & 0,0 & 56,7 & 43,3 \\
\hline
\end{tabular}

Fonte: Autores. 
Considerando o total de amostras analisadas $(\mathrm{n}=60), 6,7 \%$ apresentaram desconformidade para cor, $40 \%$ para DBO, $10 \%$ para $\mathrm{pH}$ e $43,3 \%$ para E. coli. Os demais parâmetros apresentaram $100 \%$ de conformidade com o preconizado pela legislação (Tabela 5).

\section{Discussão}

A amostras de água oriundas do tanque central e da cozinha do Parque Municipal da Matinha, Itapetinga, Bahia para o consumo, não apresentando contaminações por coliformes. Este mesmo padrão foi registrado para a quarentena, onde as coletas foram realizadas na torneira que serve de fonte de água para fornecimento aos recintos. Esta água é originária da rede de abastecimento do município, reafirmando assim a sua boa qualidade.

Nos ambientes de lagos artificiais, 4 parâmetros apresentaram desconformidade com a legislação pertinente. A cor aparente elevada nas amostras de águas do lago grande e dos jacarés reflete a presença elevada tanto de substâncias dissolvidas como também das substâncias em suspensão (BRASIL, 2005). As águas mais esverdeadas nestes ambientes amostrados indicam a elevada biomassa fitoplanctônica decorrente do enriquecimento de nutrientes e ausência de sistemas de filtração nestes locais.

Valores elevados de Potencial Hidrogeniônico $(\mathrm{pH})$ registrados no lago dos jacarés indicam que estas águas são mais alcalinas. Segundo Oliveira et al. (2009) o pH é influenciado pela quantidade de matéria orgânica a ser decomposta, sendo que a quantidade disponível de matéria orgânica vai ser inversamente proporcional ao pH. Este padrão foi corroborado no presente estudo que registrou elevados valores de $\mathrm{DBO}$ e menores de $\mathrm{pH}$.

Os elevados valores da Demanda Bioquímica de Oxigênio (DBO) registradas nos três lagos analisados (grande, jacaré e pequeno) indicam que há uma alta demanda relativa de Oxigênio necessária para estabilizar a matéria orgânica (BRASIL, 2005), ou seja que nestes ambientes há uma elevada carga de matéria orgânica que requer níveis elevados de oxigênio para a sua depuração.

O parâmetro microbiológico E. coli esteve elevado para todos os lagos analisados, refletindo que há contaminação recente por fezes de animais homeotérmicos (aves e/ou mamíferos) nestes lagos. Segundo Coelho (2015) este parque Municipal apresenta uma densidade considerável de urubus pretos, Coragyps atratus, que eliminam seus excrementos em toda a área do parque e nos recintos. Logo esta pode ser uma das fontes de contaminação dos ambientes supra citados, além das próprias fezes dos animais que vivem nestes ambientes (macacos nos lagos grandes e pequenos) e dos silvestres que visitam tais locais.

Quanto aos recintos dos periquitos e da jiboia o $\mathrm{pH}$ estava mais alcalino, acima do limite em $50 \%$ das amostras analisadas. Segundo Wetzel, (2001) o pH está diretamente relacionado com a fotossíntese do ecossistema, então quando há a elevação desta, que se dá pelo aumento de nitrogênio e fósforo, o pH da água tende a tornar-se mais alcalino por conta da diminuição das concentrações de gás carbônico na água.

Do ponto de vista microbiológico, todos os recintos avaliados apresentaram positividade para coliformes totais e $E$. coli. Indicando contaminação fecal recente nestes ambientes. Contudo os recintos das araras, avestruz, carcará, onça, jiboia e leão apresentaram concentrações de E. coli superior ao preconizado pela legislação. Estes valores elevados deve-se a contaminação pelas fezes dos animais homeotérmicos residentes (aves e mamíferos), além da visita de animais silvestres de vida livre aos recintos para se alimentarem. Essas fezes, que podem conter agentes causadores de enfermidades, costumam ser depositados sobre o solo, na água e a partir daí serem espalhadas pela chuva, vento e a própria ação de animais, contaminando o terreno e os bebedouros em questão. Os bebedouros permitem que os animais possam entrar nestes recipientes e muitas vezes 
contaminar a fonte de água com os excrementos. Assim parte da fonte de contaminação provém dos próprios animais alojados. Este mesmo padrão foi encontrado para o zoológico de Guarulhos, São Paulo, Brasil (Souza et al., 2019 e Fia et al., 2014).

Considerando os resultados aqui apresentados, a depreciação microbiológica da água ocorre no local de consumo, e não na sua origem. Tal padrão foi também registrado por Pinto et al.(2010a) para águas utilizadas na dessedentação animal numa área rural, ressaltando a necessidade de observar o estado de limpeza dos bebedouros, sendo recomendável sua instalação em locais protegidos, preferencialmente cobertos, e de fácil acesso para limpeza e troca da água. Logo a boa higiene deve ser mantida para evitar a invasão de agentes infecciosos e a propagação de ressistencia a antimicrobianos ao ambiente natural e dentro do zoológico (Ishihara et al., 2012).

A alternativa eficiente para reduzir estas contaminações bacteriológicas nas águas dos bebedouros é a cloração e desinfecção dos recipientes. Segundo Pinto et al (2010b) a manutenção da qualidade microbiológica da água usada na dessedentação de bezerras foi obtida com a utilização de cloro residual livre numa concentração inicial de $5,0 \mathrm{mg} \mathrm{L}^{-1} \mathrm{e} \mathrm{a}$ permanência da água clorada no bebedouro por no máximo sete horas seguidas.

Face ao exposto, sugere-se que para minimizar estas contaminações deva ocorrer o aumento da frequência de higienização e desinfecção dos recintos e bebedouros, além da instalação de filtros e renovação constante das águas dos lagos do Parque Municipal da Matinha. Nossos dados destacam a importância de incorporar a amostragem ambiental (monitoramento) da água na rotina para determinar os riscos a saúde animal e assim intervir no manejo do parque.

\section{Considerações Finais}

As águas utilizadas pelos animais do Parque Municipal da Matinha, Itapetinga Bahia apresentaram conformidade na maioria dos parâmetros físico-químicos avaliados. As amostras de abastecimento de água do parque apresentaram conformidade com a legislação vigente, isto é, próprias para a dessedentação dos animais. Contudo inconformidades foram registradas nos parâmetros microbiológicos (E. coli) para a maioria dos recintos dos animais indicando assim a necessidade de aumentos na frequência de higienização e desinfecção nos bebedouros dos animais. Os lagos avaliados revelaram contaminação fecal recente nas águas destes ambientes, além de inconformidades para alguns parâmetros físico-químicos. Deste modo renovação destas águas aliada a um sistema de filtração pode melhorar a sua qualidade. Portanto é evidente que o monitoramento da qualidade físico-química e microbiológica das águas utilizadas pelos animais contribui efetivamente para o diagnóstico e melhorias no manejo do parque. Futuramente sugere-se incluir a avaliação da qualidade físico-química e microbiológica na rotina do parque de modo a avaliar bimestralmente e intervir no manejo do parque.

\section{Agradecimentos}

Ao senhor Fábio Viana Santos Secretário Municipal de Meio Ambiente de Itapetinga - Bahia por permitir a realização das coletas, a Empresa Baiana de Águas e Saneamento EMBASA, em especial aos Biólogos Elly Rogério Sampaio de Souza e Eliene Campos Macedo pelo apoio e suporte nas análises. Ao Biólogo Antônio Sodré, aos graduandos em Ciências Biológicas Ítalo Brasileiro e Leomarcos Porto, aos tratadores e funcionários do Parque Municipal da Matinha pelo auxílio nas coletas.

\section{Referências}

APHA, (2017). Standard Methods for the examination of water and wastewater, American Public Health Association.

Barros, M.S., Pfal, L.A. \& Oroski, F. I. (2006). Análise da Qualidade da Água em Estabelecimentos Leiteiros Associados da Cooperativa Agropecuária Batavo-Carambeí-PR. Biblioteca Virtual Emater. 
Research, Society and Development, v. 11, n. 3, e11911326481, 2022

(CC BY 4.0) | ISSN 2525-3409 | DOI: http://dx.doi.org/10.33448/rsd-v11i3.26481

Bordalo, C. A. (2017) “O paradoxo da água na região das águas: o caso da Amazônia brasileira”, GEOUSP Espaço e Tempo (Online), 21(1), p. 120-137. doi: 10.11606/issn.2179-0892.geousp.2017.107531.

Brasil. (2005). Resolução CONAMA $n^{\circ}$ 357, de 17 de março de 2005. Dispõe sobre a classificação dos corpos de água e diretrizes ambientais para o seu enquadramento, bem como estabelece as condições e padrões de lançamento de efluentes, e de outras providências. Diário Oficial da República Federativa do Brasil, Poder Executivo.

COMPANHIA DE TECNOLOGIA DE SANEAMETO AMBIENTAL DE SÃO PAULO (CETESB). 2018. Norma técnica L5 202 Coliformes totais, coliformes termotolerantes e Escherichia coli - Determinação pela técnica de tubos múltiplos. $5^{\mathrm{a}}$ Edição.

Coelho, H.J. (2015). A unidade de conservação como laboratório para a educação ambiental: o caso do parque municipal da matinha em Itapetinga, Bahia BAHIA. UESC.

Cross-Mellor, S. K., Kent, W. D., Kavaliers, M., \& Ossenkopp, K. P. (2000). Examining the effects of lipopolysaccharide and cholecystokinin on water ingestion: comparing intake and palatability. Brain research, 861(2), 220-232. https://doi.org/10.1016/s0006-8993(00)01969-7.

Dalfovo, M. S., Lana, R. A., \& Silveira, A. (2008). Métodos quantitativos e qualitativos: um resgate teórico. Revista Interdisciplinar Científica Aplicada, 2(4), 01-13.

Dubos, R. J., \& Schaedler, R. W. (1961). The effect of bacterial endotoxins on the water intake and body weight of mice. The Journal of experimental medicine, 113(5), 921-934. https://doi.org/10.1084/jem.113.5.921.

Fernandes, M. L. B., Gouveia, R. L., Lucena, L. F. de, Rodrigues, M. da S., Silva, A. K. P. da, \& Silva, N. M. P. da R. e. (2021). Estudo de balneabilidade em quatro praias do arquipélago de Fernando de Noronha baseado em análise de coliformes totais. Research, Society and Development, 10(11), e302101119784. https://doi.org/10.33448/rsd-v10i11.19784

Fia, R., Tadeu, H.C., Menezes, J.P.C., Fia, F.R.L. \& Oliveira, L.F.C. (2015). Qualidade da água de um ecossistema lótico urbano. Revista Brasileira de Recursos Hídricos, 20(1): 267-275. https://doi.org/10.21168/rbrh.v20n1.p267-275

Freitas, M. S., Silva, S. L., Costa, E. N. \& Lessa, A. O. (2007). O Parque Municipal da Matinha como instrumento de sensibilização ambiental. Revista Eletrônica do Mestrado em Educação Ambiental, 19(1): 235-245.

Ishihara, K., Hosokawa, Y., Makita, K., Noda, J., Ueno, H., Muramatsu, Y., Ueno, H., Mukai, T., Yamamoto, H., Ito, M., \& Tamura, Y. (2012). Factors associated with antimicrobial-resistant Escherichia coli in zoo animals. Research in Veterinary Science, 93(2), 574-580. https://doi.org/10.1016/j.rvsc.2011.09.006

Itapetinga (2004). Projeto de Lei de agosto de 2004. Dispõe sobre o Parque Municipal da Matinha. Câmara Municipal de Itapetinga.

Kulka, D. D. (2014). Conforto térmico em áreas verdes urbanas no município de Itapetinga, BA. UESB, Itapetinga.

Lourenço, K. L. (2014). Doenças microbianas em aves da ordem Psittaciformes. UFMG. Disponível em: http://hdl.handle.net/1843/ICBB-BDAPQ4

Oliveira, T.M.B.F., Di Souza, L. \& Castro, S.S.L. (2009). Dinâmica da série nitrogenada nas águas da bacia hidrográfica Apodi/ Mossoró - RN - Brasil. Eclética Química, 34(3):17-26.

Orsini, H. \& Bondan, E.F. (2006). Fisiopatologia do estresse em animais selvagens em cativeiro e suas implicações no comportamento e bem-estar animalrevisão da literatura. Revista Instituto Ciências da Saúde, 24(1): 7-13.

Pereira, A. S., Shitsuka, D. M., Parreira, F. J., \& Shitsuka R. (2018). Metodologia da pesquisa científica (1a ed.). [free e-book]. Santa Maria: Núcleo de Tecnologia Educacional da Universidade Federal de Santa Maria. https://repositorio.ufsm.br/handle/1/15824

Pereira, H.D. (2015). Fisiologia do estresse e enriquecimento ambiental na melhoria do estresse em felídeos mantidos em cativeiro. UFCG. Disponível em: http://www.cstrold.sti.ufcg.edu.br/grad_med_vet/tcc_2014.2/12_helio_domingos_pereira.pdf.

Pereira, E. R., Paterniani, J. E. S., \& Demarchi, J. J. A. D. A. (2009). The importance of water quality of animal watering. Revista Brasileira De Engenharia De Biossistemas, 3(3), 227-235. https://doi.org/10.18011/bioeng2009v3n3p227-235

Pinto, F.R., Sampaio, C.F., Malta, A.S., Lopes, L.G., Pereira, G.T. \& Amaral, L.A. (2010a). Características da Água de consumo animal na Área rural da Microbacia do córrego Rico, Jaboticabal, SP. Ars Veterinaria, 26(3): 153-159. http://dx.doi.org/10.15361/2175-0106.2010v26n3p153-159

Pinto, F.D., Lopes, L.G., Faria, L.S., Nunes, A.P., \& Amaral, L.A. (2010b). Dinâmica da contaminação por indicadores bacterianos e efeito da cloração em três manejos da água de dessedentação de bezerras. Ars Veterinaria, 26(1): 26-31. http://dx.doi.org/10.15361/2175-0106.2010v26n1p026-031.

Pinto, R. C. A. B. L. (2006). Diagnóstico do Parque da Matinha como subsídio para o desenvolvimento de ações na área de Educação Ambiental. Universidade Estadual do Sudoeste da Bahia.

Saad, C. E. do P., Saad, F. M. de O. B. \& França, J. (2011). Bem-estar em animais de zoológicos. Revista Brasileira de Zootecnia = Brazilian Journal of Animal Science, 40: 38-43, Suplemento especial.

Souza, L. H. N., Arruda, R.O.M., Rosini, E.F. \& Pontes, D.D. (2019). Diagnóstico da qualidade ambiental dos lagos e nascentes do zoológico de Guarulhos, município de Guarulhos-SP. Revista Geociências-UNG-Ser, 18(1): 12-18. ttp://dx.doi.org/10.33947/1981-7428-v18n1-4078. 
Research, Society and Development, v. 11, n. 3, e11911326481, 2022

(CC BY 4.0) | ISSN 2525-3409 | DOI: http://dx.doi.org/10.33448/rsd-v11i3.26481

Veiga, G. (2005). Análises físico-químicas e microbiológicas de água de poços de diferentes cidades da região sul de Santa Catarina e efluentes líquidos industriais de algumas empresas da grande Florianópolis. Universidade Federal de Santa Catarina. https://repositorio.ufsc.br/bitstream/handle/123456789/105056/Graziella_da_Veiga.pdf?sequence=1

Wetzel, R. G. (2001). Limnology Lake and Reservoir Ecosystems. Academic Press, San Diego.

Willms, W., Kenzie, O., Mcallister, T., Colwell, D., Viera, D., Wilmshurst, J., Entz, T. \& Olson, M. (2002). Effects of Water Quality on Cattle Performance Journal of Range Management. 55: 452-460. http://dx.doi.org/10.2307/4003222. 